\title{
Nutritional Value and Quality Characteristics of Cookies Prepared from Partial or Complete Substitution of Wheat Flour
}

\author{
Abdel-Samie. M. A. S. \\ Department of Food and Dairy Sciences and Technology, Faculty of Environmental Agricultural Sciences, Suez Canal \\ University, El-Arish, North Sinai, Egypt.
}

Received: $15 / 11 / 2013$

\begin{abstract}
Effects of wheat flour substitution using buckwheat flour of levels vary from 0 to $100 \%$ (in the purpose of antioxidant enrichment and to create a new developed product with a different nutritional and aromatic profile) on dough physical properties and dynamic rheology, cookie physical properties, nutritional value and aromatic compounds profile were studied. Dough with the buckwheat incorporated flour showed lower hardness and higher stickiness. Dynamic rheology properties of buckwheat substituted cookie dough, determined as a profile of G', G', and $\delta$ were different compared to those of control samples. Moisture contents and water activity of buckwheat cookie samples were higher compared to control cookies. Spread ratios of control cookies were lower (4.63), than that of the buckwheat cookie samples, $60 \%$ substitution level showed the highest value (5.4),and control samples still lower than that of the $100 \%$ buckwheat cookie sample (5.1). Buckwheat cookies were darker than wheat cookies. Antioxidant properties of buckwheat cookies when measured by both TPC and DPPH were higher than antioxidant properties of wheat cookies. Buckwheat cookies had a different aromatic compounds profile with a good overall acceptability.
\end{abstract}

Keywords: Wheat Substitution, Cookies, Anti-Oxidant, Aromatic profile, Dynamic Rheology and Buckwheat.

\section{INTRODUCTION}

Egypt have always faced problems with the sufficiency of wheat flour for the bread making and other uses, that is why many researchers have made trials to increase the production of wheat flour or even other cereal or non-cereal sources to substitute wheat flour to solve the problem (Watzke, 1998; Ammar et al., 2009).

Antioxidant enriched foods are getting higher importance as it is nutritionally more healthy and different in taste (Abdel-Samie et al., 2010). Antioxidant compounds are therapeutic agents against diseases involving radical damage; It inhibits lipid peroxidation in food products which could also improve food quality and safety (Dietrych-Szostak and Oleszek, 1999). A diet rich in fruits, vegetables and minimally refined cereals "which are considered as a main Antioxidant sources" is associated with lower incidence of illnesses such as coronary heart disease, some forms of cancer and neurodegenerative ailments (Stangeland et al., 2009).

Buckwheat (Fagopyrium esculentum Moench) belongs to the Polygonaceae family. It is considered as a valuable additive for functional food products, successfully replaces rice or potatoes in the main menus of many countries (Dietrych-Szostak and Oleszek, 1999). Buckwheat leaves and young parts of the plant are consumed in some countries as a vegetable. Green flour, obtained by milling of the dried plants, is used as a natural food colorant (Kalinova et al., 2006). Antioxidant activities of buckwheat extracts were shown to be high even comparing to those of synthetic antioxidants (Sun and Ho, 2005). Compared to oats and barley regarding its antioxidant it was found that buckwheat had higher antioxidant activity. Buckwheat seeds and leaves were proved to be suitable food component with antioxidant effect (Holasova et al., 2002). The dietary and health value of phenolics, especially rutin, in buckwheat seeds and flour were shown to be high, while the high rutin yield in the leaves could effectively explain the therapeutic effects of leaf/herb extracts (Quettier-Deleu, et al., 2000).

Six flavonoids have been isolated and identified in buckwheat grain (rutin, orientin, vitexin, quercetin, isovitexin, and isoorientin) (Dietrych-Szostak and Oleszek, 1999). Phenolic compounds in buckwheat contained catechin and epicatechin compounds (Watanabe and Ayugase, 2009). Vitamin E and squalene were also detected in buckwheat seeds and leaves extracts (Kalinova, et al., 2006). From the watersoluble extracts of buckwheat, Guo, et al., (2007) isolated a novel antitumor (against human mammary cancer protein, coded as TBWSP31. Nephrectomized rats given buckwheat extract showed improvement in renal function, as indicated by decreased serum level of creatinine, with a significant decrease in the level of methyl guanidine, a uremic toxin produced from creatinine in the presence of hydroxyl radical (Yokozawa, et al., 2002). Buckwheat concentrate was found to be an effective source of D-CI "a chemically synthesized anti-hyperglycemic compound, and a component of an insulin mediator" for lowering serum glucose concentrations in rats and therefore may be useful in the treatment of diabetes (Kawa, et al., 2003).

Buckwheat was used to substitute $15 \%$ of wheat flour to make buckwheat enhanced breads and it was moderately acceptable by panelists (Lin, et al., 2009).

The aims of our research were to prepare better cookies with higher nutritional value and different flavor, through using buckwheat flour. It was also aimed to investigate the impact of wheat flour substitution using buckwheat flour on cookies nutritional, physical and sensory characteristics.

\section{MATERIALS AND METHODS}

Materials:

Wheat flour " $11.2 \%$ protein low-gluten" was purchased from local market of zagazig city, Egypt. 
Buckwheat flour " $10.69 \%$ protein" was obtained from Tian Xiang Ye Tian, Xiangyetian Food Co., LTD, Chifeng City, Inner Mongolia Province, China. Sugar, shortening, salt and baking soda were obtained from the local markets of Zagazig city, Egypt.

\section{Chemicals:}

Chemicals were of analytical grade and were purchased from El-Gumhorya Company except reagents including Diphenyl-picrylhydrazyl (DPPH), FolinCiocalteu $(2 \mathrm{~N})$ were purchased from Sigma-Aldrich (Germany).

\section{Methods:}

\section{Moisture:}

contents of flour and cookie samples were determined according to the AACC 44-15A method (AACC, 2002) using the one stage method because moisture contents of prepared cookies did not exceed $13 \%$.

\section{Preparation of cookies:}

Cookies were prepared according to the AACC 10$50 \mathrm{D}$ method (1999), With minor modification as we did not add dextrose solution "a browning aid reagent" because buckwheat is darker than wheat flour. Wheat flour of the base formula was substituted for buckwheat flour according to the flour blends substituting systems shown in Table.1.

Table (1): Wheat and buckwheat flours blends used to prepare buckwheat cookies

\begin{tabular}{ccc}
\hline $\begin{array}{c}\text { Sample } \\
\text { number }\end{array}$ & $\begin{array}{c}\text { Wheat } \\
\text { flour \% }\end{array}$ & $\begin{array}{c}\text { Buckwheat } \\
\text { flour \% }\end{array}$ \\
\hline Control $^{*}$ & 100 & 0 \\
BW $^{*}$ & 90 & 10 \\
BW $_{\mathbf{2 0}}$ & 80 & 20 \\
BW $_{\mathbf{3 0}}$ & 70 & 30 \\
BW $_{\mathbf{4 0}}$ & 60 & 40 \\
$\mathbf{B W}_{\mathbf{5 0}}$ & 50 & 50 \\
$\mathbf{B W}_{\mathbf{6 0}}$ & 40 & 60 \\
$\mathbf{B W}_{\mathbf{7 0}}$ & 30 & 70 \\
$\mathbf{B W}_{\mathbf{8 0}}$ & 20 & 80 \\
$\mathbf{B W}_{\mathbf{9 0}}$ & 10 & 90 \\
$\mathbf{B W}_{\mathbf{1 0 0}}$ & 0 & 100 \\
\hline
\end{tabular}

Buckwheat

\section{Dough characteristics:}

Dough hardness and stickiness of base formulated dough and buckwheat cookie dough were measured using Texture Analyzer TAXT2I (Stable Micro Systems Ltd., Surrey, UK). Force in compression mode was used under the following test conditions, $5 \mathrm{~kg}$ load cell, cylindrical probe $(25 \mathrm{~mm}$ diameter $), 2.0 \mathrm{~mm} / \mathrm{s}$ pre-test speeds, with a $1.0 \mathrm{~mm} / \mathrm{s}$ test speed and $10 \mathrm{~mm} / \mathrm{s}$ posttest speed. Dough pieces of $7 \mathrm{~mm}$ thickness were precisely centered on the texture analyzer stage and compressed by the probe which contacted the dough to a $5 \mathrm{~mm}$ distance. A positive peak value was taken as a measure for dough hardness, while the negative peak value indicated dough stickiness (Pareyt, et al., 2008).

Dynamic rheology properties of cookie dough samples prepared using different wheat and buckwheat blends were tested using a controlled stress direct strain and controlled rate Rheometer (TA, AR-G2 Rheometer. New Castle, DE, USA). Oscillatory dynamic rheological measurement was performed, with a frequency sweep test at $40{ }^{\circ} \mathrm{C}$ with two serrated plates of a $40 \mathrm{~mm}$ diameter to prevent slippage during testing (plate to plate Geometry). Also, the edges of cookie dough samples were covered by the machine's cover to prevent the samples dehydration through moisture loss. G', G', and $\tan (\delta)$ were measured over a frequency range of $0.01-20 \mathrm{~Hz}$ at a $1.5 \%$ strain.

\section{Quality attributes of cookie:}

Color was analyzed for the values " $\mathrm{L}^{*}, \mathrm{a}^{*}$ and $\mathrm{b}^{*}$ " using a Hunter lab (Ultra Scan Pro, INC, Made in Japan). $L^{*}$ value representing lightness (brightness), $a^{*}$ value redness to greenness (where $+\mathrm{a}^{*}$ indicates redness while $-a^{*}$ indicates greenness) and $b^{*}$ value yellowness to blueness $\left(+b^{*}\right.$ is yellowness while $-b^{*}$ is blueness). Chroma meter was calibrated between every two samples using a white-colored calibration plate with a serial number "USP1166" and color values $\left(\mathrm{L}^{*}=57.36\right.$, $\left.\mathrm{a}^{*}=-21.38, \mathrm{~b}^{*}=11.36\right)$.

Physical properties of different cookie samples (base formula, buckwheat substituted cookies) including thickness, diameter and spread ratios were measured according to the AACC 10-50D method (AACC, 2002). After $30 \mathrm{~min}$ of removing the cookies from the oven, six cookies were laid edge-to-edge and measured for diameter using a scale, cookies were rotated $90^{\circ}$ and remeasured for diameter again, and average of two measurements was taken and divided by 6 to get the diameter of the single cookie sample. Same number of cookies (6) was put on top of another and was measured using a caliper, then rearranged again and re-measured for thickness and average of the two values were taken and divided by 6 to get the thickness of a single cookie sample. Spread ratio was the ratio of diameter divided by thickness. Cookie moisture content was determined according to the AACC 44-15A (AACC, 2002).

Texture properties, determined as Breaking Forces of cookie samples (base formula, buckwheat substituted cookies), were evaluated according to our previous study (Abdel-Samie, et al. 2010) with a minor modification following to the recommendations of the equipment's guide. Three-point bend test was carried out using a Texture Analyzer (TATX2) Stable Microsystem, Surrey, Mono Research, to evaluate the peak breaking force $(\mathrm{kg})$ of cookies using the "force-incompression system" and a return to start cycle. A knife edge probe with a two beams stage with a $5 \mathrm{~mm}$ distance between the two beams was used. Pre-test speed was $1 \mathrm{~mm} / \mathrm{s}$, test speed was $3 \mathrm{~mm} / \mathrm{s}$ post-test speed was $10 \mathrm{~mm} / \mathrm{s}$ and a distance of $5 \mathrm{~mm}$. trigger force was $20 \mathrm{~g}$. Cookie hardness was also determined using the same equipment but with a cylinder probe of $25 \mathrm{~mm}$ diameter, pre-test speed was $2.5 \mathrm{~mm} / \mathrm{s}$, test-speed was 2 $\mathrm{mm} / \mathrm{s}$ and post-speed was $10 \mathrm{~mm} / \mathrm{s}$ with a $5 \mathrm{~mm}$ distance and a $20 \mathrm{~g}$ trigger force.

\section{Antioxidant Capacity of Prepared Cookies:}

Extraction: The cookie samples were finely grinded in a laboratory blade mill to pass through a 1.0 
$\mathrm{mm}$ screen. One gram of cookie powder was defatted using $100 \mathrm{ml} \mathrm{n}$-hexane in a soxhelt apparatus to allow refluxing for two hours to remove fats from the cookie samples powder. Defatted powder was then extracted using $50 \mathrm{~mL}$ of $80 \%$ methanol at room temperature for $1 \mathrm{~h}$ with continuous stirring using an orbital shaker. Extracts were filtered and stored at $-20^{\circ} \mathrm{C}$ until further analysis for antioxidant determination (Chan, et al., 2008).

Total phenolic contents (TPC) of the extracts of cookie samples were determined using the FolinCiocalteu method as described by (Emmons et al., 1999). Four milliliters of distilled water were mixed with $500 \mu \mathrm{L}$ saturated sodium carbonate, $250 \mu \mathrm{L}$ of sample extract and $250 \mu \mathrm{L}$ of Folin-Ciocalteu reagent diluted with water $(1: 1 \mathrm{v}: \mathrm{v})$. The mixture was allowed to stand at room temperature for $25 \mathrm{~min}$, centrifuged for 10 $\min$ at $5,000 \mathrm{xg}$ at room temperature, and the absorbance at $725 \mathrm{~nm}$ was determined. Results were expressed as mg Gallic acid equivalents (GAE) per 100 gram of sample (mg GAE/100g)

\section{Antioxidant Activity by Free-Radical-Scavenging Activity}

DPPH (1,1-diphenyl-2-picrylhydrazyl radical) was used to determine the scavenging activity of the extracts of cookie samples (control and buckwheat cookies) as described by (Tepe, et al., 2005), with slight modifications. A 2-mL aliquot of extract was added to $2 \mathrm{~mL}$ of DPPH solution $(200 \mu \mathrm{M}$ in methanol). The mixture was shaken vigorously and incubated at room temperature in the dark for $30 \mathrm{~min}$. The absorbance of the mixture was determined at $517 \mathrm{~nm}$ using a spectrophotometer (model 721E, Shanghai Spectrum Instrument Co. Ltd., China). The antioxidant activity was calculated according the following formula:

$$
\mathrm{AO} \%=\frac{\mathrm{A}_{\mathrm{DPPH}}-\mathrm{A}_{\text {sample }}}{-\mathrm{A}_{\mathrm{DPPH}}}
$$

Where $\mathrm{AO}$ is the antioxidant activity, $\mathrm{A}_{\mathrm{DPPH}}$ is the absorption of the DPPH solution, and $\mathrm{A}_{\text {sample }}$ is the absorption of the extract.

\section{Aromatic compounds:}

Aromatic compounds profile of all prepared cookies using; wheat, wheat buckwheat blends and buckwheat cookie samples were analyzed using SPME-GC by determining the volatile compounds of crashed cookie samples. Cookie samples were cut into small pieces. Five grams of cookie sample pieces were precisely weighted and were put in $15 \mathrm{~mL}$ sample bottles occupying $3 / 5$ of the bottle. Samples were reconditioned in a thermostatic water bath at $60^{\circ} \mathrm{C}$ with the maturing extraction head covering the bottle for 40min headspace extraction. SPME fibers were made back to the needle by using the handle and extract the needle to inject the sample. Volatile compounds were analyzed. Chromatograph condition were DB-WA X122-7032 AOYJ $(30 \mathrm{~m} \times 0.25 \mathrm{~mm}, 0.25 \mu \mathrm{m})$; flow of carrier gas was a certain flow of $0.8 \mathrm{ml} / \mathrm{min}$; heating procedure was to start heating on a temperature of $40^{\circ} \mathrm{C}$, keep on $40^{\circ} \mathrm{C}$ temperature for $3.5 \mathrm{~min}$, heat to $90^{\circ} \mathrm{C}$ at the rate of $5^{\circ} \mathrm{C} / \mathrm{min}$, then heat to $220^{\circ} \mathrm{C}$ at the rate of $12^{\circ} \mathrm{C} / \mathrm{min}$ and keep temperature on $220^{\circ} \mathrm{C}$ for $7 \mathrm{~min}$. Mass spectra condition were as the following: lionization way EI, the temperature of sample injecting hole $250^{\circ} \mathrm{C}$, electron energy $70 \mathrm{eV}$, emission current $200 \mu \mathrm{A}$, collecting way is full scan, mass range of collecting is $33 \sim 495 \mathrm{amu}$.

Sensory-evaluation test was carried out by 25 panelists, who were asked to evaluate the prepared cookies for color, texture, flavor, aroma and over-all acceptability on a nine-point hedonic scale, according to the following scoring system: 1- dislike extremely; 5neither like nor dislike; and 9- like extremely. Sensory evaluation of cookies provides a practical and rapid test of quality in the absence of direct methods to measure taste and aroma. The results obtained from the sensoryevaluation test enable the evaluation of food and help to judge consumer acceptance without following detailed chemical or microbiological methods.

\section{Statistical analysis:}

SPSS (version 17.0) software was used to perform the statistical analysis. One way ANOVA (analysis of variance) was performed and significant differences was considered at the level of $p \leq 0.05$. Duncan's multiplerange test was used to differentiate between the mean values. Standard deviation was also calculated and presented after the mean values.

\section{RESULTS AND DISCUSSIONS}

\section{Dough hardness and stickiness:}

Fig.1. presents cookie dough hardness of control sample (100\% wheat flour) and samples with the substitution of wheat flour using buckwheat flour at different substitution levels (0-100\%) expressed as $\mathrm{Kg}$ forces. Dough hardness of samples prepared with the substitution of wheat flour using buckwheat flour was lower than that of control dough sample. Gradual dilution of wheat flour gluten with the gradual increase of buckwheat substitution percentages caused a weakness of the gluten network and gave the cookie dough lower hardness. Maximum dough hardness was displayed by control cookie dough sample with a hardness score of $3.1 \mathrm{Kg}$, while minimum cookie dough hardness was scored when a $60 \%$ of wheat flour was substituted using buckwheat flour. Substitution of more than $60 \%$ of wheat flour using buckwheat flour increased the dough hardness again. The lower water absorption due to the absence of gluten in the buckwheat flour could be one of the main reasons of this phenomenon. Relative increase of the cookie dough hardness after substituting a $50 \%$ of wheat flour using buckwheat flour is referred to the higher starch contents in the buckwheat flour comparing to the wheat flour, buckwheat flour contain $65-75 \%$ of starch, mixed starch allowed dough hardness to increase because of the build-up structure of the starch.

Dough stickiness followed the same tendency of dough hardness changes as could be merged from Fig.1 which presented the dough stickiness $(\mathrm{Kg})$ of cookie dough samples. All cookie dough samples stickiness were significantly $(\mathrm{P} \leq 0.05)$ lower than control cookie dough sample. Control dough stickiness was $0.91 \mathrm{Kg}$ 
while the stickiness of $50 \%$ buckwheat substituted dough sample was $50 \%$ lower stickiness comparing to control dough sample with a stickiness score of 0.45 $\mathrm{Kg}$. Stickiness of the $100 \%$ buckwheat cookie dough sample was $0.66 \mathrm{Kg}$.

Lower hardness and stickiness of buckwheat substituted cookie dough were due to the lower gluten and lower gliadins contents in the buckwheat flour comparing to wheat flour (Guo et al., 2007), which caused a decrease in elasticity of the dough which caused a decrease of the dough hardness, while the decrease of gliadins was the reason of the decrease of adhesiveness which caused a decrease in stickiness of cookie dough samples with the substitution of wheat flour using buckwheat flour.

\section{Dynamic rheological properties of cookie dough samples:}

Dough dynamic rheological properties i.e. G', G' and $\delta$ showed significant variation within cookie dough prepared using different flour blends (wheat flour alone, wheat and buckwheat flour blends or buckwheat flour alone) when subjected to a frequency sweep test ranging from $0.1-20 \mathrm{~Hz}$ at 1.5 strain and at a fixed temperature $40^{\circ} \mathrm{C}$ (Fig.2. A-C). The storage dynamic modulus G' presents the energy stored in the raw materials and recovered from it per cycle and represents the elastic nature of the raw material, G" presents the loss modulus and presents the energy lost from the materials per cycle and it represents the viscous nature of the raw materials (Singh et al., 2003).

Data of storage modulus showed gradual increase in $G^{\prime}$ in all prepared cookie dough samples with the increase of frequency during the dynamic rheology test protocol. Furthermore, substitution of wheat flour using buckwheat flour within all substitution levels gradually increased the increasing rate of $G^{\prime}$ as could be seen in fig. 2.A. G' start point also increased with the substitution of wheat flour using buckwheat flour Maximal G' was obtained within samples of $100 \%$ buckwheat flour cookie dough samples which scored 9350 and after passing the dynamic rheology test protocol, G' scored maximal value (17270), while control cookie dough samples scored minimal $G^{\prime}$ ' before passing the protocol with a score of (6309) and also scored the minimal score of $G^{\prime}$ after passing the test protocol (16720).

Same trends of change of $G^{\prime}$ were observed within the G" results "Fig. 2.B." with a minimal scores for the control cookie dough samples before and after passing the dynamic rheology test protocol with a scores of "4386 and 15356" respectively, while 100\% buckwheat flour cookie dough samples scored maximum G', values before and after passing the dynamic rheology test protocol with scores "5930 and 14630" respectively.

$G^{\prime}$ and $G$ ' changes were because of the different properties and natures and characteristics between buckwheat and wheat flours, especially differences in the protein quality and fibers, wheat flour contains more gluten compared to the buckwheat flour which could be considered as gluten-free flour, which significantly affected the dynamic rheological properties of different cookie dough samples with different substitution levels. $\delta$ is a ratio relate $G^{\prime}$ to $G^{\prime}$ ', and because both modulus had the same trends of change which increased with the increase of frequency through the frequency sweep test, $\delta$ did not show big changes within the same sample, but cookie dough samples prepared using wheat flout showed lower $\delta$ compared to buckwheat flour cookie dough samples "Fig. 2.C".

\section{Spread ratios of cookie}

Table 2 presents the spread ratio of cookie samples prepared using the base formula (control sample without any wheat flour substitution) and the buckwheat flour substituted cookies of different substitution levels (10-100\%). Spread ratios of cookie samples depended on gluten contents of flour; high gluten content in the flour absorb water to build a gluten network which retain components and build a structure leading to less spread ratio; on the other hand, substitution of wheat flour with a gluten free flour "buckwheat flour" results in an increase of spread ratios of the prepared cookies. Spread ratio of control cookie sample was 4.63 and that was lower than all other prepared cookies. Maximal spread ratio was (5.38) obtained by the $60 \%$ wheat flour substituted using buckwheat flour. Gradual decrease of wheat flour with the gradual increase of buckwheat flour caused a weak structure of cookie samples and that caused a more spread ratios comparing to the control cookie samples. This finding is confirmed by the study of (Pareyt et al., 2008) who found that cookie prepared with lower gluten formula gave the highest spread ratios.

\section{Water activity of cookies:}

Water activity of cookie samples prepared without and with the wheat flour substitution using buckwheat flour is shown in Fig.3.a. Results showed that increase of substitution level by buckwheat flour increased the water activity of cookie powder. Control cookie samples had a water activity of 0.49 which was the minimal score, while water activity of buckwheat substituted cookie samples were higher than control sample, with a maximal water activity obtained in the maximum buckwheat substitution level (100\%) with a water activity of $0.56 \%$. Higher water activity in the buckwheat added cookie samples is duo to the higher fiber contents in buckwheat flour (Lin, et al., 2009) cause the retention of more water in the cookies.

\section{Moisture content of cookies}

Moisture contents of prepared cookie samples of base formula (control sample) and also with the buckwheat substitution of different levels (10-100\%) are presented in Fig.3.b. Moisture of control cookies was $7.4 \%$ which was the minimal score comparing to other cookie samples prepared using buckwheat flour. Gradual increase of buckwheat substitution level resulted in a significant increase of moisture contents, with a maximal score obtained in the $100 \%$ buckwheat cookie samples $(8.9 \%)$ which was $20 \%$ higher than control cookie sample. Higher moisture content is due to the higher fiber contents of buckwheat flour. These results are in agreement with these obtained by (Lin, et al., 2009) who reported a higher moisture contents of buckwheat bread compared to wheat bread. 


\section{Breaking forces of prepared cookies}

Breaking forces of cookie samples prepared using all formulas, wheat flour, wheat buckwheat flour blends of different substitution percentages, and buckwheat flour cookies determined using the texture analyzer (TATX2) Stable Microsystem, Surrey, Mono Research are presented in Table.2. Gradual decrease of wheat flour in the cookie formula decreased the cookie breaking force from $8455 \mathrm{~g}$ in the control cookie samples to reach the minimal value in the $60 \%$ wheat flour substituted using buckwheat flour with a breaking force of $5040 \mathrm{~g}$, which is $40 \%$ less than the control treatment, without significant differences with the $50 \%$ and $70 \%$ of wheat flour substitution. Less breaking force of the 50, 60 and 70\% wheat flour substituted cookie samples is due to the lower gluten contents of buckwheat flour comparing to the gluten contents of wheat flour (Kreft, Fabjan et al. 2006). Higher substitution levels of buckwheat flour increased cookies breaking force again to reach $7466 \mathrm{~g}$. Relative increase of the cookies breaking forces is referred to the higher starch contents in the buckwheat flour comparing to the wheat flour. Buckwheat flour contains $65-75 \%$ of starch (Choi and Ma 2007). Gelatinized starch after cookies baking allowed breaking force to increase because of the build-up structure of the gelatinized starch. Breaking force of the $100 \%$ buckwheat cookie samples was $7466 \mathrm{~g}$ which is $12 \%$ less than breaking force of the control sample.

\section{Cookie color}

Color values of prepared cookies are shown in Table.2. Color was analyzed as three values, $\mathrm{L}^{*}, \mathrm{a}^{*}$ and $b^{*}$. Table.2. shows a gradual decrease of $L^{*}$ values with the gradual increase in substitution level of wheat flour by buckwheat flour. Lightness of control cookie samples was 61.65 while substitution of $100 \%$ of wheat flour using buckwheat flour decreased $L^{*}$ value by $16 \%$ compared to the control sample cookies with a score of 51.56. It could be noticed that, substituting up to $50 \%$ wheat flour using buckwheat flour did not change $\mathrm{L}^{*}$ value significantly $(\mathrm{P} \leq 0.05)$, but substituting more than $60 \%$ gave a significant differences of $L^{*}$ values. Same trend of $\mathrm{L}^{*}$ values changes was observed in $\mathrm{a}^{*}$ values (Table.1). Statistically, cookie samples with a 50\% wheat flour substituted using buckwheat flour was same to control cookie, while substitution of $60 \%$ or more of wheat flour using buckwheat flour significantly increased the $\mathrm{a}^{*}$ values $(\mathrm{P} \leq 0.05)$. $\mathrm{a}^{*}$ value of control cookie sample was 10.17 , while the $100 \%$ substituted cookies (buckwheat cookie samples) was $21 \%$ higher than control cookie samples with a score of 12.28. Effects of the substitution of wheat flour using buckwheat flour on cookie color was mainly reflected on the $b^{*}$ values, as it could be seen in Table. 2 . It indicated that substitution of more than $20 \%$ of wheat four using buckwheat flour decreased the $b^{*}$ values significantly $(\mathrm{P} \leq 0.05)$. $\mathrm{b}^{*}$ values of control cookie samples was 35.1 , substitution of $100 \%$ wheat flour using buckwheat flour decreased $b^{*}$ values by $19 \%$ with $a b^{*}$ value of 38.4. Concluding that buckwheat cookie samples were darker than wheat cookies, gradual increase of buckwheat gave higher redness and less yellowness cookie samples.

\section{Sensory evaluation}

The sensory characteristics of cookies prepared using the substitution of wheat flour using buckwheat flour of different levels were conducted to determine the acceptability of the product. Cookie samples were evaluated for surface, color, surface appearance, texture, taste, flavor and overall quality on a 9-point hedonic scale, Over-All acceptability scores are presented in Fig. 4. Over-All acceptability scores of cookies prepared using up to $60 \%$ of buckwheat were not significantly different compared to the control cookies while $70 \%$ substitution of wheat flour using buckwheat flour or more were significantly affected the over-all acceptability comparing to control cookies. Substitution of 10,20 and $30 \%$ of wheat flour using buckwheat flour in the preparation of cookies increased the over-all acceptability significantly from 8.4 in control cookies to $8.44,8.76$ and 8.64 in 10,20 and $30 \%$ substituted cookies respectively. $100 \%$ buckwheat cookies with the minimum over-all acceptability score was 6.24 which is still accepted to consumer and this score means that cookies with $100 \%$ buckwheat and $0 \%$ of wheat flour was slightly liked, and that gives the buckwheat flour great chance to be used in the substitution of wheat flour to prepare cookies and maybe other products.

Higher moisture contents and higher water activity of buckwheat substituted cookie samples were reflected on two parameters, first is cookie hardness and breaking forces and also were noticed by the consumer when a sensory evaluation was applied to test consumer's acceptability of cookie samples prepared using buckwheat flour as blend with wheat flour of different ratios or alone. Gradual increase of buckwheat gave higher redness and less yellowness cookie samples, which was reflected to the less preferred color scores when cookie samples were evaluated by panelists.

\section{TPC of cookie samples}

TPC of cookie samples, and its relationship to the substitution of wheat flour using buckwheat flour is presented as a linear relationship between the substitution\% and TPC in Fig.5.A. Data show that TPC of prepared cookies followed the buckwheat substitution $\%$ linearly with $\mathrm{R}^{2}$ of 0.93 . Control sample without any wheat flour substituted had the lowest TPC value among other samples with a $110 \mathrm{mg}$ GAE/100g, while substitution of wheat flour using buckwheat flour gradually increased the TPC and reached its maximal value $230.66 \mathrm{mg} \mathrm{GAE} / 100 \mathrm{~g}$ when cookies were prepared using a $100 \%$ of buckwheat flour. These results are in accordance with the study of (Lin et al., 2009) who prepared an antioxidant enrichment of bread when a $25 \%$ buckwheat flour together with wheat flour was used.

\section{DPPH scavenging activities of cookies}

Antioxidant properties of cookie samples determined using DPPH scavenging activity, followed the same trends of TPC properties of cookies as was noticed in Fig.5.B. DPPH scavenging activities of buckwheat cookies were higher than that of control 
cookie samples prepared without the addition of buckwheat flour. Control cookie samples scavenged $33 \%$ of the DPPH free radical and that was the minimal DPPH scavenging activity among all tested cookie samples. Gradual increase of buckwheat flour caused a highly significant increase of DPPH scavenging activity which was $85 \%$ correlated to the substitution percentage of buckwheat flour instead of wheat flour in the prepared cookies. Maximal DPPH scavenging activity was scored by the maximal buckwheat flour substituted cookies $(100 \%)$, DPPH scavenging activity of $100 \%$ substituted buckwheat cookies was $85 \%$. Higher scavenging activity of buckwheat substituted cookies is duo to the higher scavenging activity of buckwheat flour comparing to wheat flour.

Antioxidant properties of buckwheat cookies measured using both TPC and DPPH scavenging activities assays was correlated to the substitution percentages of wheat flour using the buckwheat flour. Buckwheat flour was reported to be higher antioxidant activity comparing to wheat flour

\section{Aromatic compounds profile of cookie volatile compounds}

Aromatic compounds data of all cookie samples; wheat flour, wheat-buckwheat flours blends of different levels and buckwheat flour are presented in Table.3. It was noted that many volatile compounds decreased with the decrease of wheat flour level in the cookie formula, those decreased compounds were as following: Trans1,3-diacetoxy-1-propene, Levulinic acid, Toluene, 2-npentylfuran, 1-hydroxy-2-butanone, nitrohexane, 2methyl-butyl acetate, 2-cyclopentene-1,4-dione, 2-(2ethoxyethoxy)ethanol, 2-decenal, 2-undecenal, 2(5H)furanone, 2,4-decadienal, 2,4-decadienal, and 2-ethyl-3hydroxyhexyl ester of 2-methyl-propionic. Those volatile compounds started to decrease with the decrease of wheat flour; interestingly those compounds totally disappeared in the buckwheat cookie samples with the absence of wheat flour in the cookie formula. While a group of other volatile compounds were not found in the control cookies which formulated of $100 \%$ wheat flour without any buckwheat flour, those compounds are: Butanal, 2-methyl, Ethanol, Ethyl butyrate, dl-limonene, Pentyl alcohol, dimethylnitrosamine, 6-methyl-5-hepten-2-one, 4dimethylamino-pyridine, 4-nitrophthalamide, ndecaldehyde, 2-nonenal, Octilin, and Delta laurolactone. These differences of volatile compounds, both cases; new compounds appeared or compounds disappearedwas the reason of the different flavor and aroma of cookie samples prepared using different flour blends or streams. Further determinations and studies of aromatic compounds and relation to the sensory evaluation are needed.

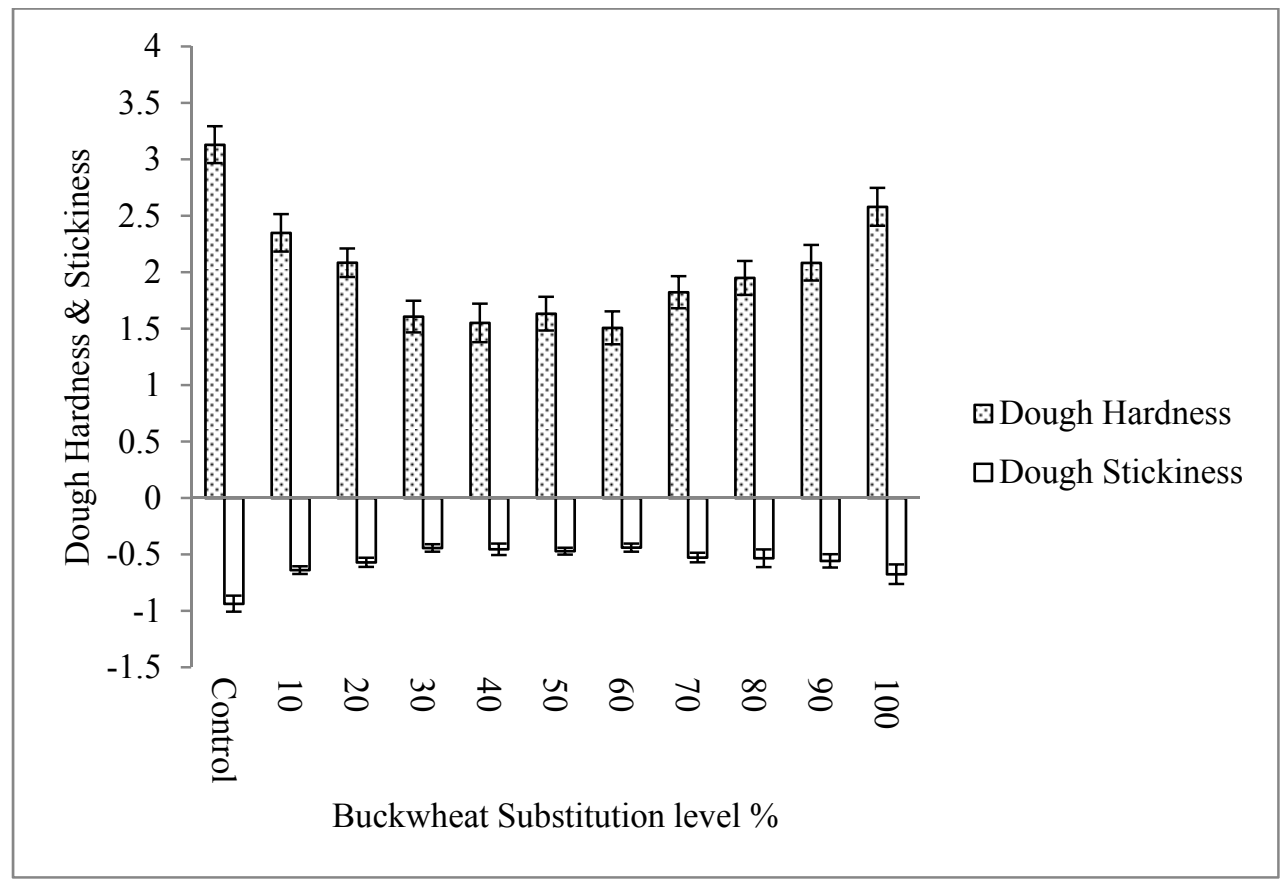

Fig. (1): Effect of wheat flour substitution using buckwheat flour on cookie dough hardness and stickiness 
Dynamic Rheology (G' "Pa" )

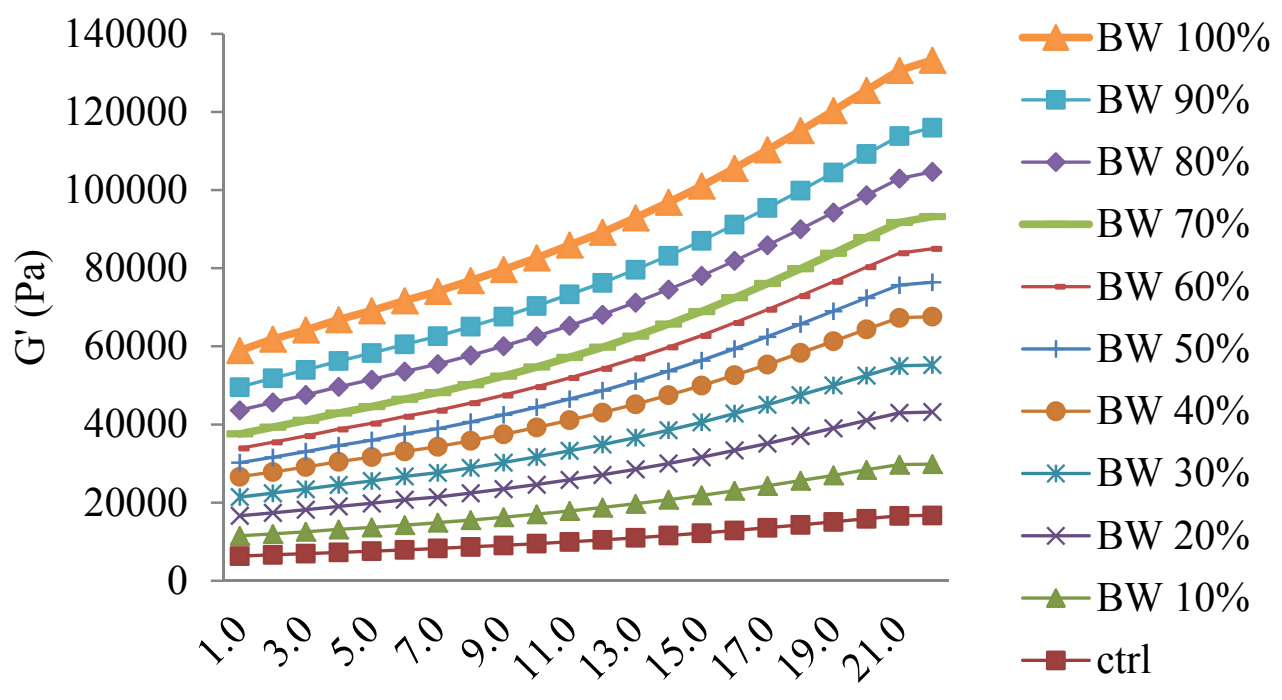

Frequency "Hz"

Fig. (2 A.): Effect of wheat flour substitution using buckwheat flour on dynamic rheology (G') of cookie dough samples

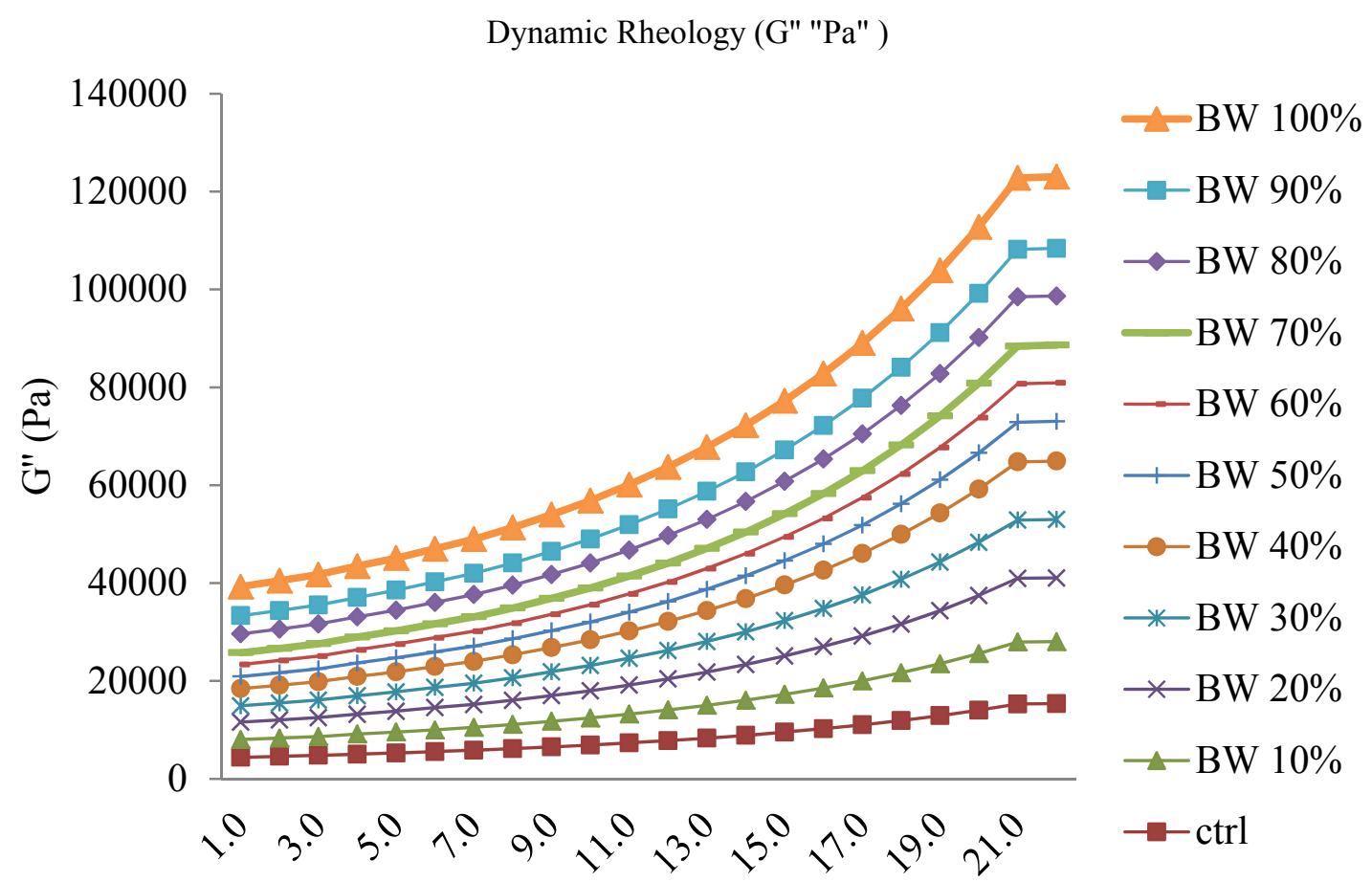

Frequency "Hz"

Fig. (2.B.): Effect of wheat flour substitution using buckwheat flour on dynamic rheology"G" of cookie dough samples. 


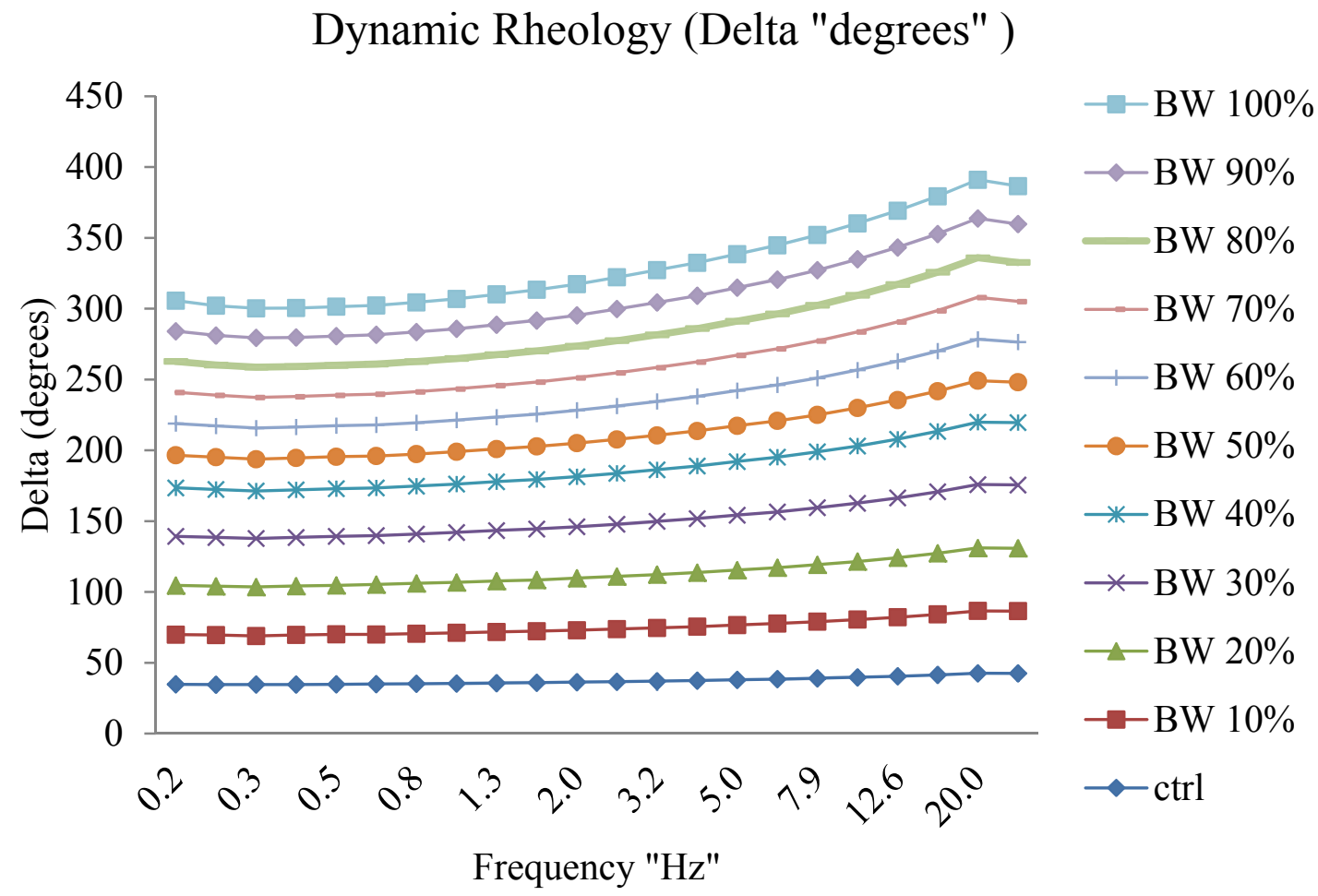

Fig. (2.C.): Effect of wheat flour substitution using buckwheat flour on dynamic rheology (delta) of cookie dough samples

Table (2): Effect of Wheat flour substitution using buckwheat flour on some physical properties of cookie samples including spread ratio, breaking forces and color values

\begin{tabular}{|c|c|c|c|c|c|c|c|}
\hline \multicolumn{3}{|c|}{ Treatment } & \multirow{2}{*}{$\begin{array}{l}\text { Spread } \\
\text { ratio }\end{array}$} & \multirow{2}{*}{$\begin{array}{c}\text { Breaking } \\
\text { forces }(\mathrm{Kg})\end{array}$} & \multicolumn{3}{|c|}{ Color } \\
\hline Wheat\% & $B W * \%$ & Code & & & $\mathbf{L}^{*}$ & $a^{*}$ & $\mathbf{b}^{*}$ \\
\hline 100 & 0 & Ctrl & $4.63 \pm 0.07$ & $8.46 \pm 0.36$ & $61.65 \pm 1.13$ & $10.17 \pm 0.53$ & $35.10 \pm 1.37$ \\
\hline 90 & 10 & BW10 & $4.90 \pm 0.05$ & $7.98 \pm 0.27$ & $61.13 \pm 1.90$ & $10.53 \pm 0.38$ & $33.11 \pm 0.76$ \\
\hline 80 & 20 & BW20 & $5.12 \pm 0.05$ & $7.42 \pm 0.29$ & $60.30 \pm 0.92$ & $10.99 \pm 0.81$ & $32.36 \pm 1.66$ \\
\hline 70 & 30 & BW30 & $5.26 \pm 0.06$ & $6.83 \pm 0.26$ & $60.46 \pm 2.20$ & $11.16 \pm 0.55$ & $30.62 \pm 1.24$ \\
\hline 60 & 40 & BW40 & $5.29 \pm 0.06$ & $6.12 \pm 0.21$ & $60.08 \pm 1.89$ & $11.24 \pm 0.57$ & $29.82 \pm 1.37$ \\
\hline 50 & 50 & BW50 & $5.39 \pm 0.05$ & $5.68 \pm 0.36$ & $58.98 \pm 1.76$ & $11.66 \pm 0.86$ & $29.70 \pm 0.53$ \\
\hline 40 & 60 & BW60 & $5.38 \pm 0.06$ & $5.04 \pm 0.24$ & $58.79 \pm 1.32$ & $11.69 \pm 0.69$ & $29.73 \pm 1.13$ \\
\hline 30 & 70 & BW70 & $5.32 \pm 0.04$ & $5.38 \pm 0.23$ & $57.62 \pm 2.20$ & $11.96 \pm 0.42$ & $29.51 \pm 0.95$ \\
\hline 20 & 80 & BW80 & $5.19 \pm 0.05$ & $6.10 \pm 0.21$ & $56.88 \pm 1.42$ & $11.99 \pm 0.89$ & $29.10 \pm 1.10$ \\
\hline 10 & 90 & BW90 & $5.11 \pm 0.05$ & $6.59 \pm 0.36$ & $54.29 \pm 1.63$ & $12.08 \pm 0.81$ & $29.03 \pm 0.58$ \\
\hline 0 & 100 & $\begin{array}{c}\text { BW10 } \\
0\end{array}$ & $5.09 \pm 0.07$ & $7.47 \pm 0.28$ & $51.56 \pm 1.49$ & $12.28 \pm 0.94$ & $28.40 \pm 1.09$ \\
\hline
\end{tabular}


Table (3): Effect of wheat flour substitution using buckwheat flour on aromatic compounds profile of prepared cookies

\begin{tabular}{|c|c|c|c|c|c|c|c|}
\hline \multirow{3}{*}{ Compound } & \multirow{3}{*}{ Formula } & \multirow{3}{*}{$\begin{array}{l}\text { Retention } \\
\text { time }\end{array}$} & \multicolumn{5}{|c|}{ Sample } \\
\hline & & & \multirow{2}{*}{$\begin{array}{l}\text { Ctrl - } \\
\text { cookie }\end{array}$} & \multicolumn{4}{|c|}{ Buckwheat cookie samples } \\
\hline & & & & $\begin{array}{l}\text { BW } \\
10 \% \\
\end{array}$ & $\begin{array}{l}\text { BW } \\
60 \% \\
\end{array}$ & $\begin{array}{c}\text { BW } \\
\mathbf{7 0 \%}\end{array}$ & $\begin{array}{c}\text { BW } \\
100 \%\end{array}$ \\
\hline Acetone & C3H6O & 2.62 & 4.51 & 4.48 & 5.17 & 5.27 & 6.23 \\
\hline Butanal, 2-methyl & C5H10O & 3.81 & - & - & - & 0.67 & 0.74 \\
\hline Ethanol & $\mathrm{C} 2 \mathrm{H} 6 \mathrm{O}$ & 4.28 & - & 0.39 & 0.68 & 1.04 & 1.19 \\
\hline Trans-1,3-diacetoxy-1-propene & C7H10O4 & 4.34 & 1.16 & - & - & - & - \\
\hline Levulinic acid & $\mathrm{C} 5 \mathrm{H} 8 \mathrm{O} 3$ & 4.35 & 1.2 & 0.71 & - & - & - \\
\hline 2,3-butanedione & $\mathrm{C} 4 \mathrm{H} 6 \mathrm{O} 2$ & 5.13 & 4.94 & 7.22 & 4.36 & 6.22 & 5.94 \\
\hline Ethyl butyrate & $\mathrm{C} 6 \mathrm{H} 12 \mathrm{O} 2$ & 6.59 & - & - & 0.60 & 0.75 & 1.06 \\
\hline Toluene & C7H8 & 6.60 & 0.64 & 0.40 & - & - & - \\
\hline 2,3-pentanedione & $\mathrm{C} 5 \mathrm{H} 8 \mathrm{O} 2$ & 7.23 & 0.75 & 1.02 & 1.21 & 1.33 & 1.51 \\
\hline n-hexanal & C6H12O & 7.78 & 2.44 & 3.76 & 3.94 & 4.12 & 4.24 \\
\hline 1-methoxy-2-propanol & $\mathrm{C} 4 \mathrm{H} 10 \mathrm{O} 2$ & 9.12 & 0.87 & 0.82 & 3.15 & 4.18 & 9.82 \\
\hline 3-methyldecane & $\mathrm{C} 11 \mathrm{H} 24$ & 9.59 & 0.38 & 0.47 & 0.50 & 0.58 & 0.71 \\
\hline n-heptaldehyde & $\mathrm{C} 7 \mathrm{H} 14 \mathrm{O}$ & 10.26 & 0.59 & 0.82 & 1.02 & 1.26 & 1.41 \\
\hline dl-limonene & $\mathrm{C} 10 \mathrm{H} 16$ & 10.52 & - & - & 1.75 & 2.31 & 5.68 \\
\hline n-dodecane & $\mathrm{C} 12 \mathrm{H} 26$ & 10.60 & 1.17 & 1.11 & - & - & - \\
\hline p-diazine & C4H4N2 & 10.79 & 0.40 & 0.44 & 0.39 & 0.37 & 0.35 \\
\hline 2-n-pentylfuran & $\mathrm{C} 9 \mathrm{H} 14 \mathrm{O}$ & 11.15 & 0.42 & 0.39 & 0.33 & - & - \\
\hline Pentyl alcohol & $\mathrm{C} 5 \mathrm{H} 12 \mathrm{O}$ & 11.54 & - & 0.33 & 0.44 & 0.49 & 0.5 \\
\hline methylpyrazine & C5H6N2 & 11.76 & 2.12 & 2.18 & 1.97 & 1.97 & 1.51 \\
\hline 2,2,4,6,6-pentamethylheptane & $\mathrm{C} 12 \mathrm{H} 26$ & 11.89 & 1.11 & 0.66 & 1.28 & 1.24 & 1.25 \\
\hline 2,2,11,11-tetramethyldodecane & $\mathrm{C} 16 \mathrm{H} 34$ & 12.03 & 2.42 & 2.60 & 2.59 & 2.42 & 2.26 \\
\hline dimethylnitrosamine & $\mathrm{C} 2 \mathrm{H} 6 \mathrm{~N} 2 \mathrm{O}$ & 12.26 & - & - & 9.31 & 9.49 & 10.64 \\
\hline Acetol & $\mathrm{C} 3 \mathrm{H} 6 \mathrm{O} 2$ & 12.28 & 11.67 & 11.55 & 10.83 & 10.11 & 10.01 \\
\hline 2-heptenal & $\mathrm{C} 7 \mathrm{H} 12 \mathrm{O}$ & 12.63 & 0.54 & 0.59 & 0.40 & 0.57 & 0.80 \\
\hline 2,6-dimethylpyrazine & C6H8N2 & 12.75 & 0.40 & 0.44 & 0.68 & 0.44 & 0.43 \\
\hline 6-methyl-5-hepten-2-one & $\mathrm{C} 8 \mathrm{H} 14 \mathrm{O}$ & 12.81 & - & - & - & - & 0.35 \\
\hline n-hexanol & $\mathrm{C} 6 \mathrm{H} 14 \mathrm{O}$ & 13.05 & 0.35 & 0.44 & 0.65 & 1.05 & 1.43 \\
\hline 1-hydroxy-2-butanone & $\mathrm{C} 4 \mathrm{H} 8 \mathrm{O} 2$ & 13.32 & 1.88 & 1.53 & 0.84 & 0.65 & - \\
\hline 4-dimethylamino-pyridine & C7H10N2 & 13.82 & - & - & 0.45 & 0.58 & 0.68 \\
\hline Ethyl caprylate & $\mathrm{C} 10 \mathrm{H} 20 \mathrm{O} 2$ & 14.10 & 13.17 & 13.48 & 13.34 & 13.17 & 13.89 \\
\hline Ethylic acid & $\mathrm{C} 2 \mathrm{H} 4 \mathrm{O} 2$ & 14.24 & 2.58 & 3.12 & 4.15 & 3.66 & 4.91 \\
\hline furfural & $\mathrm{C} 5 \mathrm{H} 4 \mathrm{O} 2$ & 14.44 & 5.44 & 4.64 & 4.95 & 4.61 & 5.01 \\
\hline 4-nitrophthalamide & $\mathrm{C} 8 \mathrm{H} 7 \mathrm{~N} 3 \mathrm{O} 4$ & 14.65 & - & - & - & - & 0.41 \\
\hline nitrohexane & $\mathrm{C} 6 \mathrm{H} 13 \mathrm{NO} 2$ & 14.88 & 0.92 & 0.95 & 0.94 & - & - \\
\hline n-decaldehyde & $\mathrm{C} 10 \mathrm{H} 20 \mathrm{O}$ & 14.88 & - & - & - & - & 0.56 \\
\hline Ketone, 2-furyl methyl & $\mathrm{C} 6 \mathrm{H} 6 \mathrm{O} 2$ & 14.95 & 1.33 & 0.90 & 0.52 & 0.45 & 0.46 \\
\hline Artificial almond oil & C7H6O & 15.19 & 0.49 & 0.51 & 0.59 & 0.58 & 0.63 \\
\hline 2-methyl-butyl acetate & $\mathrm{C} 7 \mathrm{H} 14 \mathrm{O} 2$ & 15.33 & 0.90 & 0.67 & - & - & - \\
\hline 2-nonenal & $\mathrm{C} 9 \mathrm{H} 16 \mathrm{O}$ & 15.33 & - & 0.47 & 0.61 & 0.64 & 1.05 \\
\hline Octilin & C8H18O & 15.51 & - & - & 0.30 & 0.36 & 0.45 \\
\hline 2-cyclopentene-1,4-dione & $\mathrm{C} 5 \mathrm{H} 4 \mathrm{O} 2$ & 15.87 & 0.53 & 0.38 & - & - & - \\
\hline 2-hendecanone & $\mathrm{C} 11 \mathrm{H} 22 \mathrm{O}$ & 15.99 & 0.67 & 0.52 & 0.49 & 0.71 & 0.63 \\
\hline 2-(2-ethoxyethoxy)ethanol & C6H14O3 & 16.23 & 2.61 & 2.92 & 4.44 & 2.00 & \\
\hline Butyric acid & $\mathrm{C} 4 \mathrm{H} 8 \mathrm{O} 2$ & 16.23 & - & - & - & & 0.97 \\
\hline Ethyl decanoate & $\mathrm{C} 12 \mathrm{H} 24 \mathrm{O} 2$ & 16.38 & 2.65 & 2.34 & 2.13 & 2.43 & 2.42 \\
\hline 2-decenal & $\mathrm{C} 10 \mathrm{H} 18 \mathrm{O}$ & 16.48 & 0.40 & 0.31 & - & - & - \\
\hline Furfuryl alcohol & $\mathrm{C} 5 \mathrm{H} 6 \mathrm{O} 2$ & 16.58 & 14.50 & 10.94 & 5.58 & 3.36 & 1.42 \\
\hline Salicylaldehyde & $\mathrm{C} 7 \mathrm{H} 6 \mathrm{O} 2$ & 16.89 & - & - & 0.53 & 0.66 & 0.99 \\
\hline Isobornylisovalerate & $\mathrm{C} 11 \mathrm{H} 20 \mathrm{O} 4$ & 17.41 & 0.43 & 0.40 & 0.40 & 0.45 & 0.56 \\
\hline 2-undecenal & $\mathrm{C} 11 \mathrm{H} 20 \mathrm{O}$ & 17.57 & 0.37 & 0.17 & - & - & - \\
\hline $2(5 \mathrm{H})$-furanone & $\mathrm{C} 4 \mathrm{H} 4 \mathrm{O} 2$ & 17.64 & 0.89 & 0.69 & 0.45 & - & - \\
\hline 2,4-decadienal & $\mathrm{C} 10 \mathrm{H} 16 \mathrm{O}$ & 18.14 & 0.33 & - & - & - & - \\
\hline Lauric acid, ethyl ester & $\mathrm{C} 14 \mathrm{H} 28 \mathrm{O} 2$ & 18.36 & - & 0.32 & 0.33 & 0.36 & 0.39 \\
\hline 2,4-decadienal & $\mathrm{C} 10 \mathrm{H} 16 \mathrm{O}$ & 18.37 & 0.33 & - & - & - & - \\
\hline 2-ethyl-3-hydroxyhexyl ester of 2-methyl-propionic acid & $\mathrm{C} 12 \mathrm{H} 24 \mathrm{O} 3$ & 18.62 & 0.46 & 0.39 & - & - & - \\
\hline Benzenemethanol & $\mathrm{C} 7 \mathrm{H} 8 \mathrm{O}$ & 18.77 & - & - & 0.31 & 0.38 & 0.46 \\
\hline 4-hydroxynonanoic acid lactone & $\mathrm{C} 9 \mathrm{H} 16 \mathrm{O} 2$ & 20.16 & 4.15 & 4.17 & 4.24 & 4.25 & 4.95 \\
\hline 2H-pyran-2-one,6-butyltetrahydro- & $\mathrm{C} 9 \mathrm{H} 16 \mathrm{O} 2$ & 20.63 & 0.40 & 0.45 & 0.60 & 0.60 & 0.70 \\
\hline Delta.decalactone & $\mathrm{C} 10 \mathrm{H} 18 \mathrm{O} 2$ & 21.54 & 0.89 & 0.96 & 1.05 & 1.05 & 1.25 \\
\hline $\begin{array}{l}\text { 4H-pyran-4-one, 2,3-dihydro-3,5-dihydroxy-6- } \\
\text { methyl- }\end{array}$ & C6H8O4 & 22.04 & 0.74 & 0.98 & 1.75 & 1.78 & 1.91 \\
\hline Delta.laurolactone & $\mathrm{C} 12 \mathrm{H} 22 \mathrm{O} 2$ & 23.48 & - & - & - & - & 0.34 \\
\hline
\end{tabular}




\section{Water Activity}

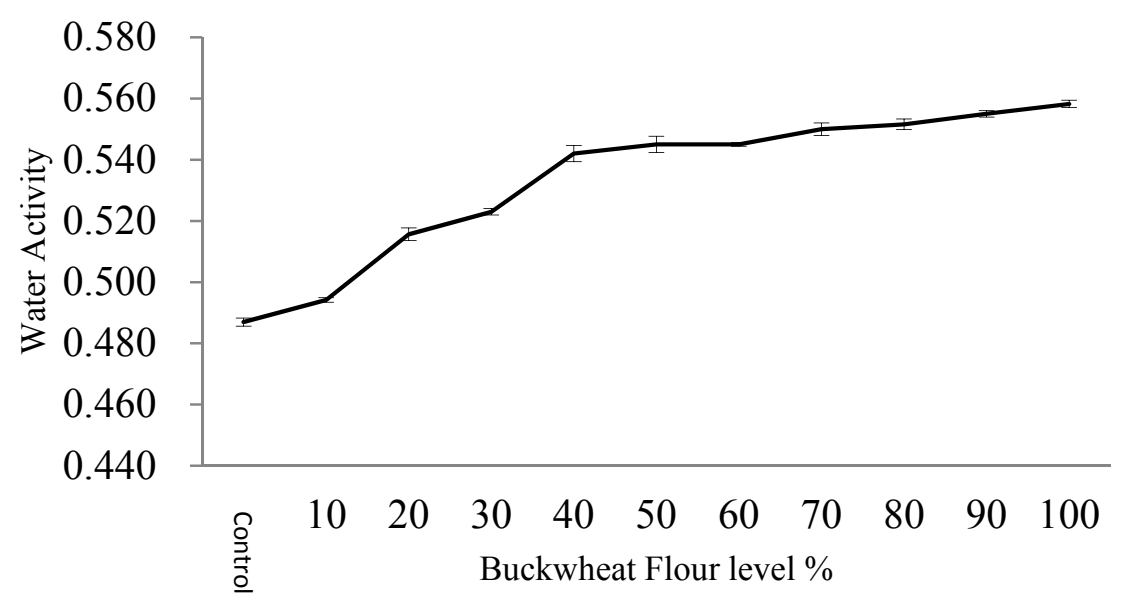

Fig. (3.A.): Effects of wheat flour substitution using buckwheat flour on water activity of cookie samples

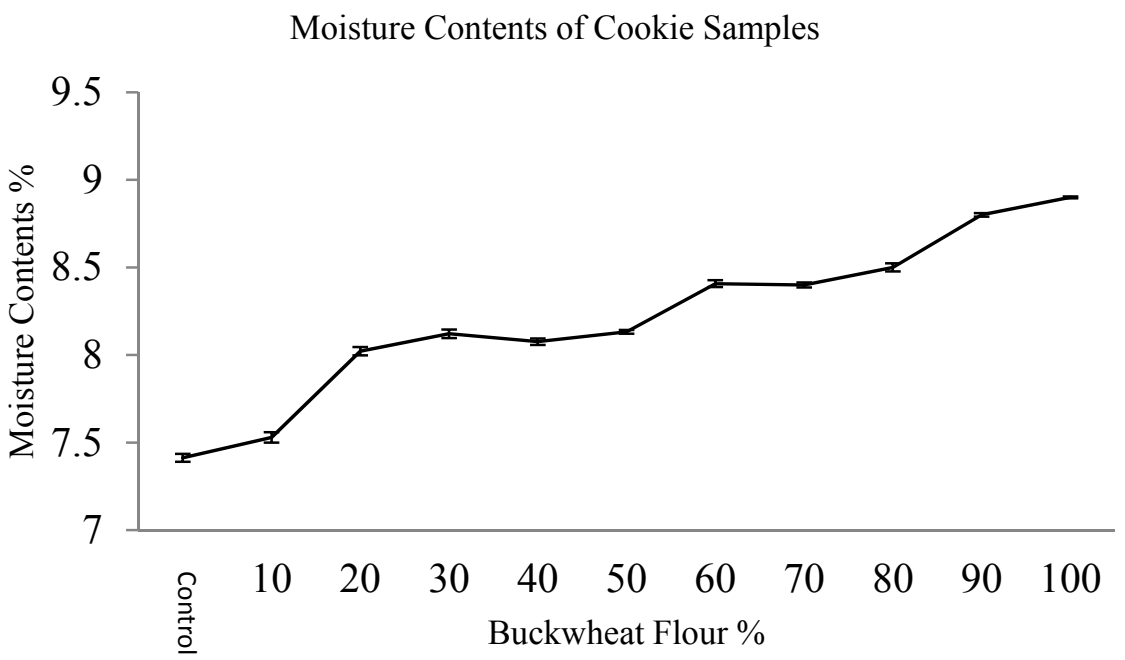

Fig. (3.B.): Effects of wheat flour substitution using buckwheat flour on moisture contents of cookie samples

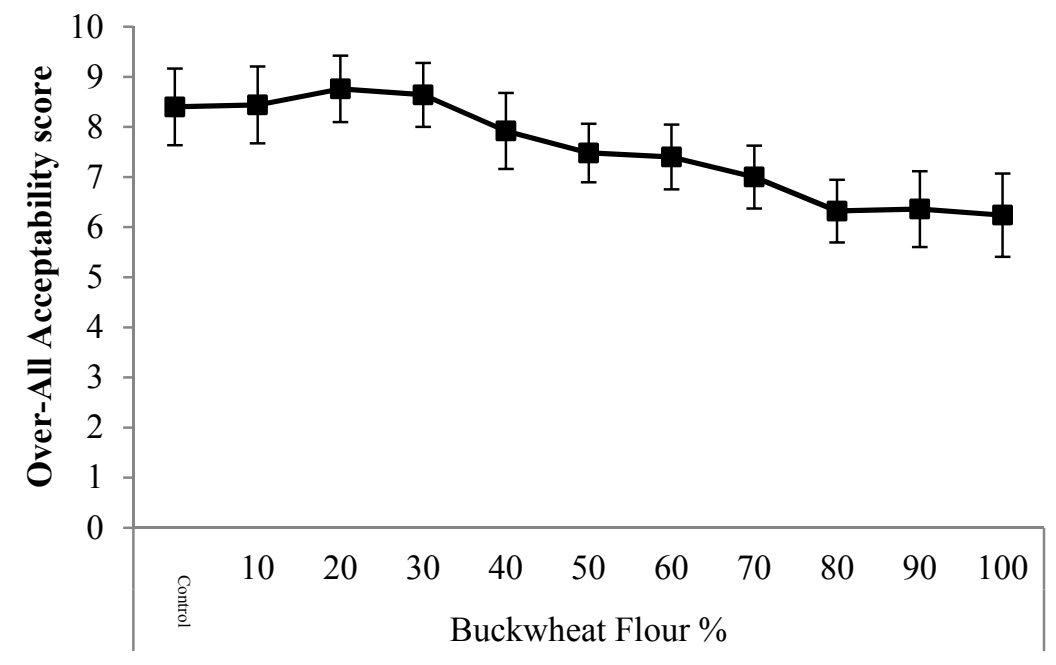

Fig. (4): Effect of wheat flour substitution using buckwheat flour on the sensory evaluation (Over all acceptability score). 


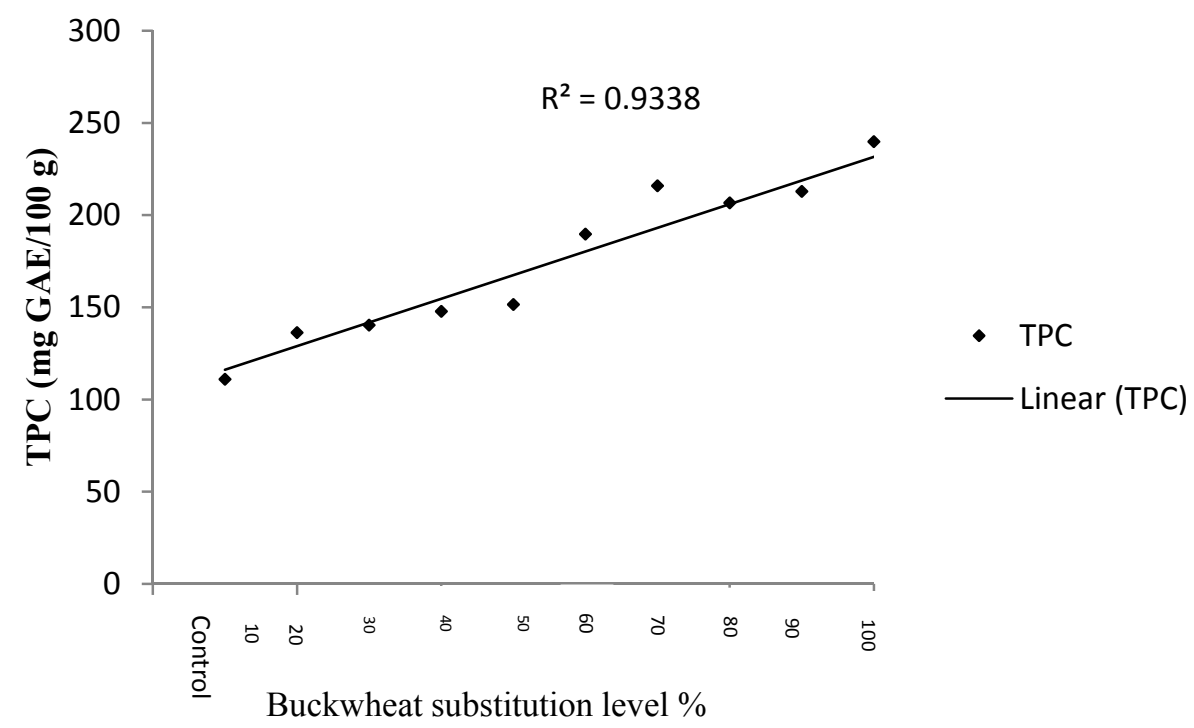

Fig. (5.A.): Linear relation between the increase of the wheat flour substitution using buckwheat flour and TPC of cookie samples

DPPH Scavenging activities

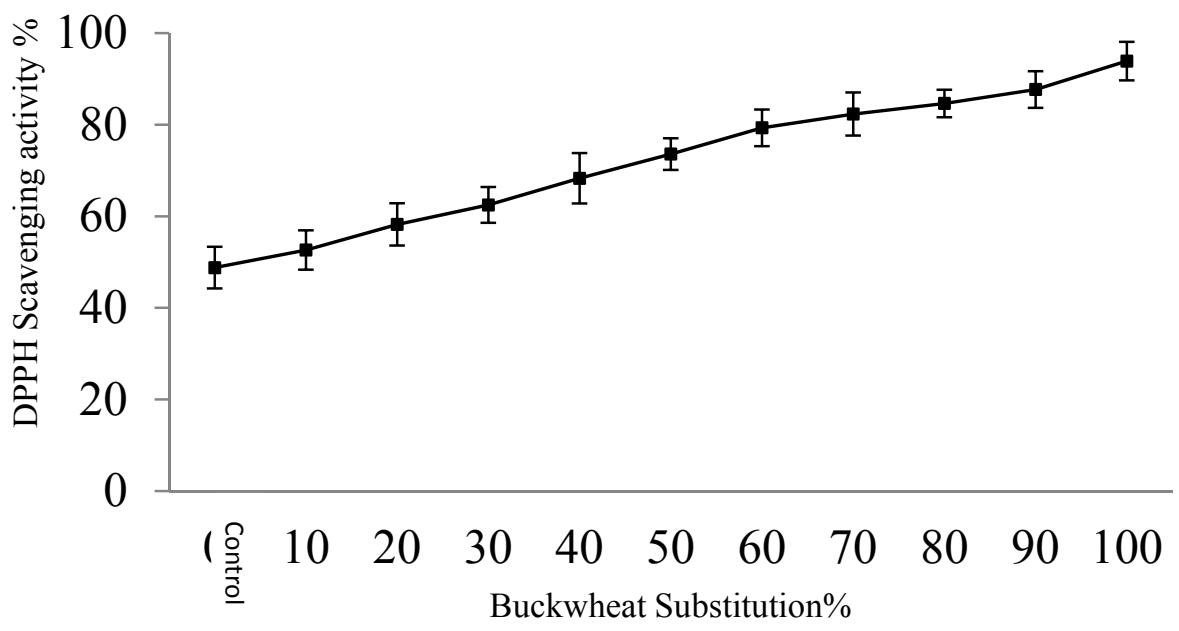

Fig. (5.B.): DPPH scavenging activity of cookie prepared using different wheat flour substitution percentages using buckwheat flour.

\section{CONCLUSION}

Substitution of wheat flour using buckwheat either partially or complete, enriched the nutritional value of cookies and created a different aromatic profile with a non-significantly difference in sensory attributes, gives a possibility of gluten-free or lower gluten products with a higher antioxidant, higher nutritional value cookies and open a way towards new products using Buckwheat.

\section{REFERENCES}

AACC. (2002). Approved Methods of Analysis, Methods 10-50D, 44-15 and 46-12. AACC International: St. Paul, MN. .

AACC. (1999). Approved Methods of the American Association of Cereal Chemists. AACC International: St. Paul, MN. .
Abdel-Samie, M. A.-S., J. Wan , W. Huang, O. K. ChungandB. $\mathrm{Xu}$ (2010). Effects of Cumin and Ginger as Antioxidants on Dough Mixing Properties and Cookie Quality. Cereal Chemistry, 87(5), 454-460. doi: 10.1094/cchem-01-10-0012

Ammar, M. S., A. E.Hegazy andS. H. Bedeir (2009). Using of Taro Flour as Partial Substitute of Wheat Flour in Bread Making. World Journal of Dairy \& Food Sciences, 4(2), 94-99.

Chan, E. W. C., Y. Y. Lim, L. F. Wong, F. S. Lianto, S. K. Wong, K. K. Lim, C. E. Joe, \& T. Y. Lim (2008). Antioxidant and tyrosinase inhibition properties of leaves and rhizomes of ginger species. Food Chemistry, 109(3), 477-483.

Choi, S. M., \& C. Y. Ma, (2007). Structural characterization of globulin from common buckwheat (Fagopyrum esculentum Moench) 
using circular dichroism and Raman spectroscopy. Food Chemistry, 102(1), 150-160.

Dietrych-Szostak, D. and W. Oleszek (1999). Effect of Processing on the Flavonoid Content in Buckwheat (Fagopyrum esculentum Molench) Grain. Journal of Agricultural and Food Chemistry, 47, 4384-4387.

Emmons, C. L., D. M. Peterson, \& G. L. Paul, (1999). Antioxidant Capacity of Oat (Avena sativa L.) Extracts. 2. In Vitro Antioxidant Activity and Contents of Phenolic and Tocol Antioxidants. Journal of Agricultural and Food Chemistry, 47(12), 4894-4898.

Guo, X., K. Zhu, H. Zhang and H. Yao (2007). Purification and Characterization of the Antitumor Protein from Chinese Tartary Buckwheat (Fagopyrum tataricum Gaertn.)Water-Soluble Extracts. J. Agric. Food Chem., 55,6958-6961.

Holasova, M., V. Fiedlerova, H. Smrcinova, M. Orsak, J. Lachman andS.Vavreinova (2002). Buckwheat-the source of antioxidant activity in functional foods. Food Research International, 35(2-3), 207-211.

HU, C. and D. D. KITTS (2000). Studies on the Antioxidant Activity of Echinacea Root Extract. Journal of Agricultural and Food Chemistry, 48, 1466-1472.

Kalinova, J., J. Triska andN. Vrchotova (2006). Distribution of Vitamin E, Squalene, Epicatechin, and Rutin in Common Buckwheat Plants (Fagopyrum esculentum Moench). J. Agric. Food Chem., 54 5330-5335.

Kawa, J. m., C. g. Taylor andR. Przybylski (2003). Buckwheat Concentrate Reduces Serum Glucose in Streptozotocin-Diabetic Rats. J. Agric. Food Chem. 517287-7291.

Kreft, I., N. Fabjan andK. Yasumoto (2006). Rutin content in buckwheat (Fagopyrum esculentum Moench) food materials and products. Food Chemistry, 98(3), 508-512. doi: 10.1016/j.foodchem.2005.05.081
Lin, L.-Y., H.-M. Liu, Y.W. Yu,S. D. Lin and J.L. Mau (2009). Quality and antioxidant property of buckwheat enhanced wheat bread. Food Chemistry, 112(4), 987-991.

Pareyt, B., E. Wilderjans, H. Goesaert, K. Brijs andJ. A. Delcour (2008). The role of gluten in a sugarsnap cookie system: A model approach based on gluten-starch blends. Journal of Cereal Science, 48(3), 863-869.

Quettier-Deleu, C., B. Gressier, J. Vasseur, T. Dine, C. Brunet, M. Luyckx and F. Trotin (2000). Phenolic compounds and antioxidant activities of buckwheat (Fagopyrum esculentum Moench) hulls and flour. Journal of Ethnopharmacology, 72(1-2), 35-42.

Singh, J., N. Singh, T. R. Sharma andS. K. Saxena (2003). Physicochemical, rheological and cookie making properties of corn and potato flours. Food Chemistry, 83, 387-393

Stangeland, T., S. F. Remberg, \& K. A. Lye, (2009). Total antioxidant activity in 35 Ugandan fruits and vegetables. Food Chemistry, 113(1), 85-91.

Sun, T. and C.T. Ho (2005). Antioxidant activities of buckwheat extracts. Food Chemistry, 90(4), 743749.

Tepe, B., M. Sokmen, H. A. Akpulat, \& A. Sokmen, (2005). In vitro antioxidant activities of the methanol extracts of four Helichrysum species from Turkey. Food Chemistry, 90(4), 685-689.

Watanabe, M. andJ. Ayugase (2009). Chiral Separation of Catechins in Buckwheat Groats and the Effects of Phenolic Compounds in Mice Subjected to Restraint Stress. Journal of Agrical and Food Chemistry, 57, 6438-6442.

Watzke, H. J. (1998). Impact of processing on bioavailability examples of minerals in foods. Trends in Food Science \& Technology, 9(8-9), 320-327.

Yokozawa, T., H. Y. Kim, G. i. Nonaka, andK. Kosuna (2002). Buckwheat extract inhibits progression of renal failure. J. Agric. Food chem., 50, 33413345

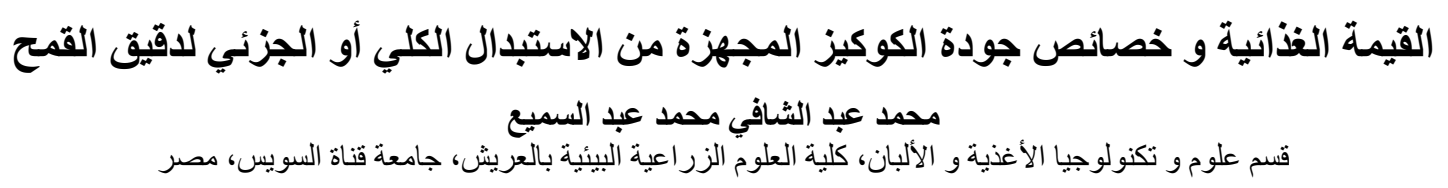

فى هذا البحث تمت در اسة تأثير استبدال دقيق القمح بدقيق الحنطة السوداء (بمستويات تتباين من الصفر و حتى الاحلال الكلي بهدف

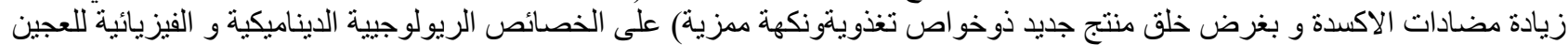

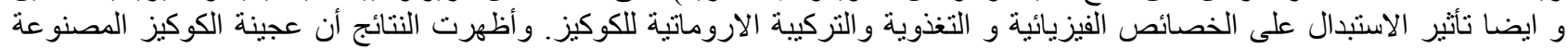

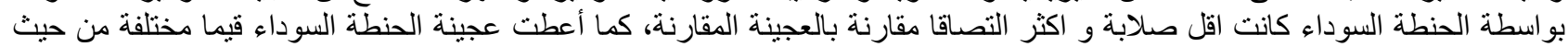

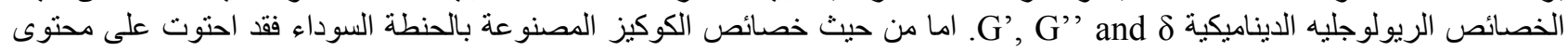

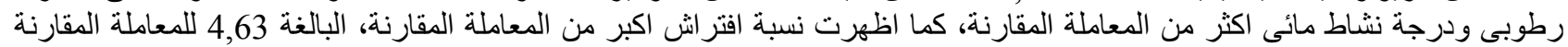

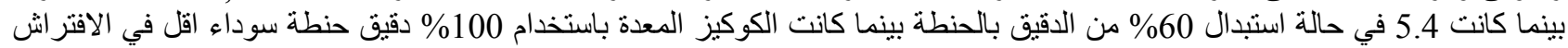

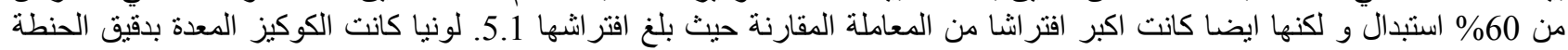

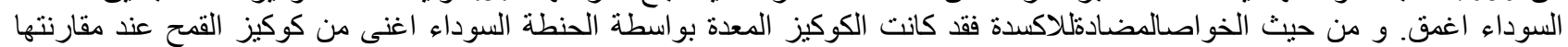

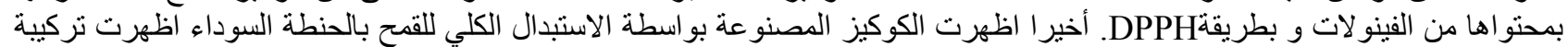
مختلفة عن المعاملة المقارنة مع الاحتفاظ بالقبول عند تقبيمها حسيا. 